\title{
Designs for the future: the role of sustainable irrigation in northern Australia
}

\author{
J. K. Camkin ${ }^{1,2}$, K. L. Bristow ${ }^{1,2}$, C. Petheram ${ }^{1}$, Z. Paydar ${ }^{1}$, \\ F. J. Cook ${ }^{1,2,} \&$ J. Story ${ }^{1}$ \\ ${ }^{I}$ CSIRO Land and Water, Australia \\ ${ }^{2}$ Cooperative Research Centre for Irrigation Futures, Australia
}

\begin{abstract}
Northern Australia (NA) accounts for $40 \%$ of the Australian landmass, is largely undeveloped and is one of the few large natural areas remaining on earth. The interplay between the landscapes, rivers, groundwater and strongly monsoonal weather pattern has resulted in unique, diverse and iconic ecological systems that will need special attention to ensure their integrity is retained as development pressure increases. With 60 to $70 \%$ of Australia's fresh water discharging from tropical rivers, and reduced water availability in much of southern Australia due to drought, climate change and increasing water demand, there is rapidly growing interest in the land and water resources of the north.

The Australian Government has recognised this growing pressure and that there is a unique and historic opportunity to ensure the management and use of Australia's northern land and water resources takes place within a strategic, sustainable framework. Taking this opportunity requires forethought about the future of NA and what role irrigation should play in that future. Key questions are whether irrigation should play a significant role, and if so, where should it be located, what should it look like and how should it be managed? Established in 2003, Northern Australia Irrigation Futures (NAIF) is a collaboration of four governments responsible for NA, research organisations and industry developing new knowledge, tools and processes to support debate and decision-making about the future of irrigation in NA.

NAIF exhibits many of the characteristics of the emerging discipline of implementation and integration science. It has been a catalyst for further work to help understand and deal with the many complexities and uncertainties relating to decisions about the future of irrigation in NA.
\end{abstract}

Keywords: Northern Australia Irrigation Futures, irrigation, hydrology, mosaics, decision-making, implementation and integration science. 


\section{Introduction}

There is a unique and historic opportunity to ensure that management of Australia's northern water resources takes place within a strategic, ecologically, culturally and economically sustainable framework (Government of Australia [1]). Northern Australia (NA) is defined here as that area north of the Tropic of Capricorn - approximately $40 \%$ of Australia's land mass (Figure 1).

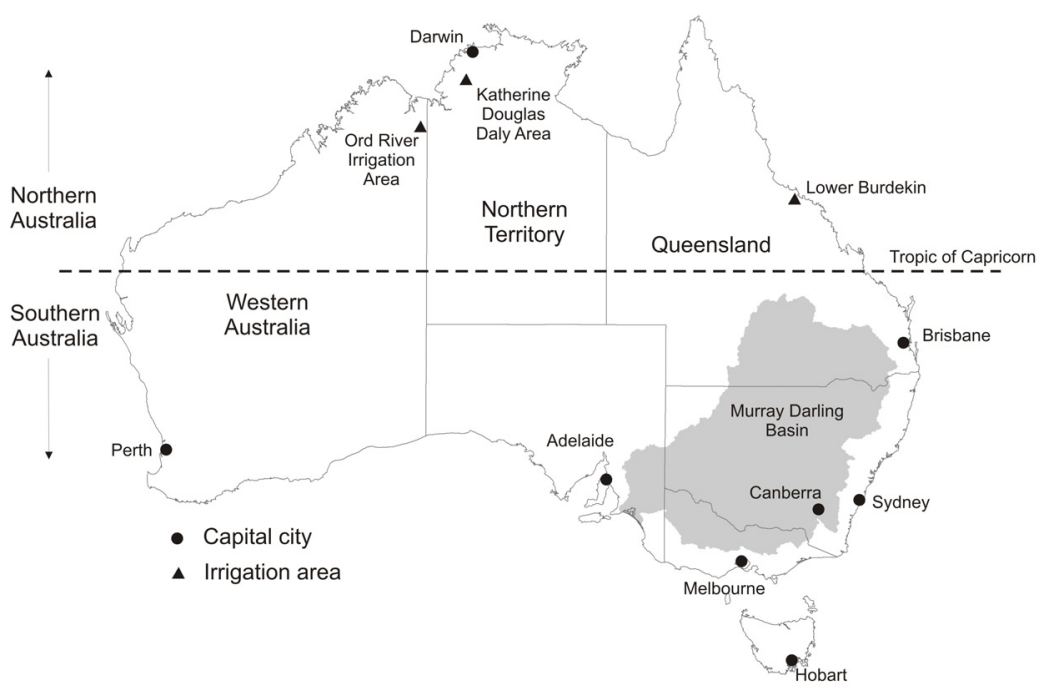

Figure 1: $\quad$ Map of Australia.

The $2^{\text {nd }}$ World Water Development Report (UNESCO [2]) predicted the world will need 55\% more food by 2030. Nationally, there is mismatch between water availability and demand. 60 to $70 \%$ of Australia's freshwater runoff occurs in the north but greater than $80 \%$ of the population lives in five expanding southern coastal cities where the increasing urban footprint, drought, climate change and increasing demand are reducing the water available for irrigation. Together, these trends are increasing pressure for development of the water and land resources of NA, and increasing public and political debate on this important national issue.

The uniqueness of northern landscapes and ecosystems has been strongly influenced by the quantity, quality and timing of water flows through the catchments. For Indigenous Australians, the surface and groundwater systems of the north have a strong cultural significance (Jackson [3]) and for many other Australian's the ecosystems of the north also hold an iconic status. There is growing recognition of these values and of the potential for irrigation and other water use to impact on them. Policy initiatives reflect these changing values and 
irrigation development proponents face unprecedented scrutiny of their proposals.

Three recent initiatives are recognition of the increase in public, scientific and political focus on NA and are of major significance to the question of the future role of irrigation in NA. The Northern Australia Irrigation Futures project (NAIF) was established in 2003 to develop new knowledge, tools and processes to support debate and decision-making about irrigation in NA and to encourage strategic thinking (see http:/www.clw.csiro.au/naif/). The Tropical Rivers and Coastal Knowledge (TRaCK) hub (see http://www.track.gov.au/) was established in 2007 to provide the science and knowledge that government, communities and industries need for the sustainable use and management of Australia's tropical rivers and estuaries. In January 2007 Prime Minister Howard released a National Plan for Water Security (Australian Government [1]). The new Rudd Government has confirmed its commitment to a Northern Australia Land and Water Taskforce to examine the range of development opportunities in NA that impact on land and water resources (Wong [4]). The Taskforce will be informed by Northern Australia Land and Water Futures Assessments. The remainder of this paper focuses on NAIF.

\section{Northern Australia Irrigation Futures}

\subsection{Background}

NAIF is a collaboration of the Australian, Queensland, Northern Territory and Western Australian Governments, the Cooperative Research Centre for Irrigation Futures, the National Program for Sustainable Irrigation and Australia's Commonwealth Scientific and Industrial Research Organisation (CSIRO). It involves targeted research focussing on improving understanding of the links between irrigation and the quantity and quality of downstream water systems (particularly groundwater), and the relationship between irrigation and the ecological, economic and social systems within which it takes place. Working with northern governments, and guided by a representative and skills based Steering Committee, researchers are developing frameworks that support strategic thinking and decision-making about irrigation.

\subsection{The hydrology, context and history of irrigation in northern Australia}

Cultivated agriculture and irrigation developments are not new to NA. Several irrigation schemes, such as the Lower Burdekin, Pioneer and Mareeba schemes in north Queensland are over 100 years old, and irrigation at the Ord River in Western Australia has been in operation for over 40 years (Petheram et al. [5]). Other irrigation developments collapsed very soon after they commenced operation (e.g. Humpty Doo; Mollah [7]). Numerous studies and reports have examined the reasons for European development either failing or never starting in the north of Australia. A much cited factor is a failure to understand the northern environment (Woinarski and Dawson [6]). 
NAIF has laid foundations for understanding the hydrology of NA by providing a broad overview of the surface and groundwater resources with respect to irrigation development. The literature on the hydrology of NA was reviewed and some key biophysical issues, opportunities and constraints for irrigation identified. Particular emphasis was placed on illustrating the differences between water systems in NA (tropical) and those of the Mediterranean and temperate southern Australia - the latter being more familiar to most Australians (Petheram and Bristow [8]).

Because of its position and the orientation of the Australian continent within the global circulatory system, NA is characterised by high year-round temperatures, a distinct seasonal rainfall pattern, some of the greatest rainfall intensities in the world, large inter-annual variability in rainfall and large evaporation rates. Due to of a lack of rainfall irrigation is essential for cultivated agriculture or perennial horticulture during the dry season (May to November). High evaporation rates during the dry season mean that a greater volume of water is required to irrigate a given area than in the south (Petheram and Bristow [8]). Twelve major drainage basins characterise the Australian continent. Half of these are partly or entirely located within NA, and approximately $60 \%$ of Australia's runoff is generated in the north (NLWRA [9]). Streamflow in NA is strongly seasonal and has a large inter-annual variability compared with rivers of similar climate elsewhere in the world (Petheram et al. [10]). This means that permanent settlements and irrigation during the dry season requires surface water storage structures, unless suitable groundwater resources are available (Petheram and Bristow [8]).

NAIF examined three well known irrigation areas to draw out experiences and lessons relevant to northern Australia. The three focus areas were the well established Lower Burdekin (LB), the expanding Ord River Irrigation Area (ORIA); and the emerging Katherine-Douglas-Daly Area (KDDA). The LB is NA's largest irrigation area with approximately 80000 ha of land under irrigation, predominantly sugarcane. The ORIA is a 13,000 ha surface water scheme with plans for further expansion. The KDDA is an evolving irrigated area of 2,200 ha located within the Daly River catchment. The Daly River is one of the few perennial rivers in the Northern Territory and has the largest dry season flows. These flows are central to the variety of unique ecosystems that inhabit the Daly river catchment (Erskine et al. [11]). Unlike the other two irrigation areas, the KDDA has no in-stream storages. The perennial flows and groundwater yields make the region attractive to irrigators and of high ecological and cultural significance (Petheram et al. [10]). Considering past experiences in both northern and southern Australia, and from other tropical regions of the world, will be important to avoiding a repeat of problems that have plagued irrigation developments around the world. Success will require transparency and accountability to local communities, ongoing monitoring and early identification of emerging problems, and funding to deal with unexpected problems that invariably occur well after development (Petheram et al. [10]). 


\subsection{Irrigation mosaics: a possible alternative approach to irrigation}

Most irrigation areas in Australia are characterised by large-scale contiguous irrigation systems. Irrigation mosaics, discrete patches of irrigated land dispersed across the landscape, may offer an alternative and could be particularly attractive for delivering improved social and economic opportunities for rural and remote communities in NA. However, the longer-term environmental impacts of irrigation mosaics are still largely unknown (Paydar et al. [12]). NAIF examined some of the issues associated with irrigation mosaics, focussing on their biophysical effects compared to large scale contiguous irrigation systems (Figure 2).

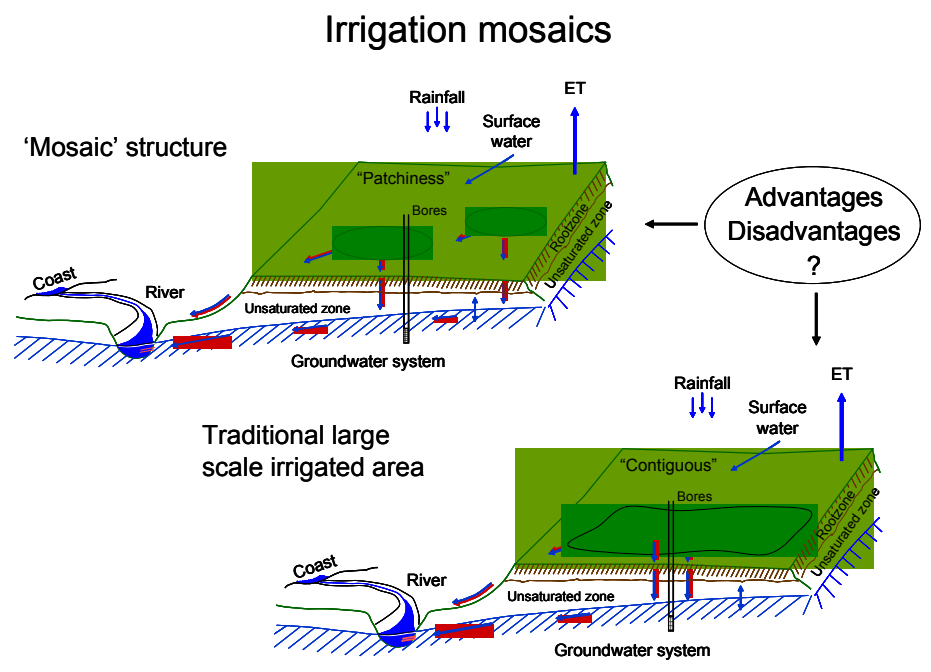

Figure 2: $\quad$ Irrigation mosaics $\mathrm{v}$ contiguous areas (Cook et al. [13]).

Documented knowledge on irrigation mosaics and implications within the context of sustainable development was found to be very limited. However, there are some findings from studies of other systems, with spatial patterns in the landscape, which can be used to help with analysis of irrigation mosaics (Paydar et al. [12]).

From ecological research it appears that patch size, shape and spatial arrangement are important characteristics in landscape analysis. For conservation planning, the bigger the reserves, the closer together, the more circular, and the more they are linked by habitat corridors, the better they serve the purpose of nature conservation. Irrigation mosaics could be used to create or enhance ecotones in the landscape for greater biodiversity, adjusting the microclimate, minimising erosion, and in absorption of surplus material (nutrients, sediments, solutes) flowing from the surrounding fields, thus decreasing the discharge out of an irrigation area, a possible environmental off-site effect. Conversely, fragmentation, involving discontinuity of patches, can increase the vulnerability of patches to external disturbance (e.g. wind storms, droughts; Paydar et al. [12]). 
Based on the literature review it appears that irrigation mosaics could have both negative (more lateral recharge, salinisation, increased operational losses) and positive (filtering nutrient surplus, enhanced biodiversity, preventing erosion, reduced area of impact around the irrigation area, lower rate of watertable rise) effects on the environment (Paydar et al. [12]).

New analytical and numerical solutions and programs that considerably reduce computation time were also developed to help analysis of spatial and temporal issues associated with irrigation mosaics. This research also suggests that irrigation mosaics could have both negative (e.g. higher evapotranspiration, increased operational losses) and positive (e.g. reduced water-table height, but noting there may be an increased area affected by a rise in water table) effects on the environment. The actual benefit will depend on a range of factors including the size of individual patches, spacing between patches, and assimilative capacity of surrounding areas). The potential impacts of irrigation mosaics need careful study, and design criteria (size, shape, density, connectivity and spatial arrangement in harmony with the landscape) need to be established because environmental benefits may be short lived if space and time lags just delay unwanted consequences (Cook et al. [13]).

\subsection{Frameworks to support irrigation decision-making}

Water and irrigation decisions are complex and there are many uncertainties. Recent experiences in the Murray Darling Basin (Figure 1), for example, have increased awareness of the risks and consequences of water use decisions. Communities now expect developments to not only have acceptable environmental impacts but also deliver social and economic benefits to the community. Non-government organisations and individuals are better trained, connected and equipped to monitor decisions. Together, these trends are increasing pressure on decision-makers and dealing with complexity and uncertainty emerges as a shared need and responsibility for government, developers and the community so that good decisions can continue to be made (Camkin et al. [14]).

NAIF initially aimed to "...deliver a framework based on sustainability indicators and management criteria at a range of scales...”. Thinking about the framework changed as issues of complexity, uncertainty, resilience, risk and adaptive management emerged through the research. Focus shifted away from a simple set of biophysical indicators to frameworks to support communities and decision-makers deal with complexity and uncertainty in a comprehensive, transparent and inclusive way (Camkin et al. [15]).

In complex decisions there is a need to understand and address the difference between uncertainty and risk. The matrix created by considering at every scale (e.g. on-site, local, catchment) all of the potential environmental, social, economic and external factors that may be relevant to a decision is very large. However, not all of those potential factors are relevant to a particular decision and not all of those that are relevant are of equal importance. NAIF has worked with governments and stakeholders to develop tools to aid understanding of these differences so that managers and the community can be confident effort is 
focused on the most important issues. A prototype framework was developed for the LB consisting of an ESD Component Tree system, a web-based catchment knowledge platform and processes for improving the integration of science, policy, stakeholders and industry (Figure 3).

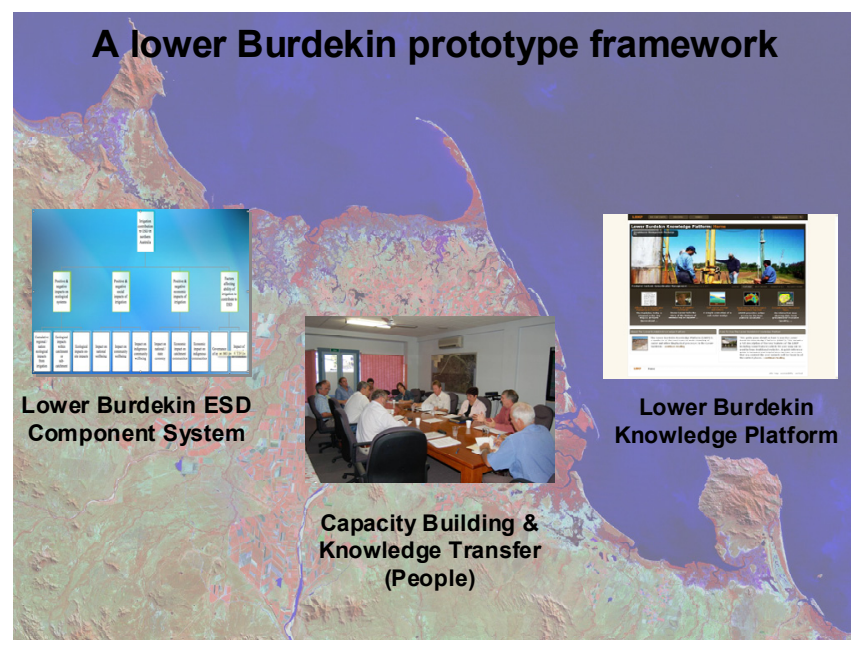

Figure 3: A lower Burdekin prototype framework (Camkin et al. [14]).

Economic activity is part of and takes place within the social system, which in turn is part of and takes place within the ecological system. The key question is not whether an industry or individual development is sustainable but rather what positive and negative contributions it makes across the full range of ESD (Chesson et al. [16]). ESD Component Tree systems that identify the factors relevant to a particular industry, proposal, or location, have been successfully applied in fisheries, aquaculture, agriculture, and irrigation reporting. NAIF has developed an ESD Component Tree approach to support irrigation decisionmaking in NA (Figure 4; Camkin et al. [14]).

There is rapid growth in the development of on-line technology that utilises new approaches to learning and supports communities of practice in the resolution of complex problems. NAIF has applied these approaches to develop a prototype catchment knowledge platform for the LB. The platform will help the community progressively build and tell the story of how the catchment operates in a biophysical, social, economic sense and governance sense.

\section{Conclusion}

The range of concerns expressed about irrigated agriculture in NA highlights the need for irrigation design to be part of a much broader development planning process that considers physical and economic aspects of resources as well as cultural, social and ethical values. The relatively small number of players in NA 


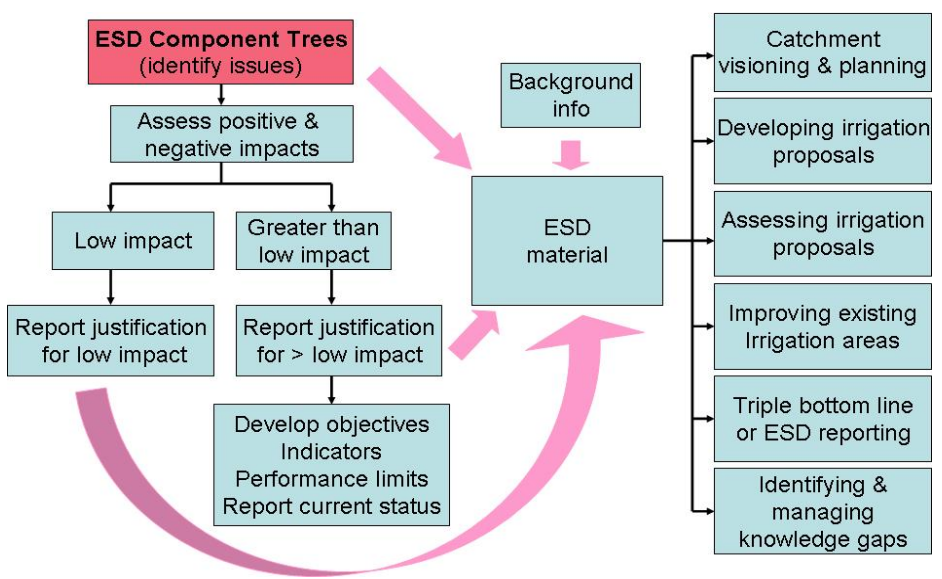

Figure 4: Applications for ESD Component Trees (Camkin et al. [14]).

provides a unique opportunity for collaboration and strategic planning. NAIF exhibits features consistent with those described by Bammer [17] as characteristic of integration and implementation science. Firstly, the project aimed to find better ways to deal with the complexity, uncertainty, change and imperfections in understanding of irrigation in NA. Secondly, the project was conducted consistent with the three theoretical and methodological pillars of integration and implementation science, namely (i) systems thinking and complexity science; (ii) participatory methods; and (iii) knowledge management, exchange and implementation. Thirdly, NAIF is grounded in practical implementation, with a focus on developing practical tools for decision-makers and the community, and involved collaboration with a wide range of government, industry, community, and research stakeholders relevant to NA.

\section{References}

[1] Australian Government (2007). A National Plan for Water Security. 26 January 2007.

[2] UNESCO (2006). Water a shared responsibility. The United Nations World Water Development Report 2.

[3] Jackson, S. (2004). Preliminary report on Aboriginal perspectives on landuse and water management in the Daly River region, northern Territory. A report to the northern Land Council.

[4] Wong, P. (2008). Elevated role and more expertise for Northern Australia Land and Water Taskforce. Media Release. Senator the Hon Penny Wong, Minister for Climate Change and Water Resources, Australian Government. 25 January 2008.

[5] Petheram, C., Tickell, S., O’Gara, F., Bristow, K.L., Smith, A. and Jolly, P. (2008a). Analysis of the Lower Burdekin, Ord and Katherine-Douglas-Daly Irrigation Areas: Implications to future design and management of tropical 
irrigation. CSIRO Land and Water Science Report 2008, CRC for Irrigation Futures Technical Report No. 04/07 101 pp.

[6] Woinarski, J. and Dawson, F. (1997). Limitless lands and limited knowledge: coping with uncertainty and ignorance in northern Australia. In Ecology, Uncertainty and Policy: managing ecosystems for sustainability. (eds.) Norton, T.W., Handmer, J.W. \& Dovers, S.R. Cambridge University Press.

[7] Mollah, W.S. (1982). Humpty Doo - rice in the Northern territory. North Australia Research unit. Monograph, Darwin. ANU Press Canberra.

[8] Petheram, C. and Bristow, K.L. (2008). Towards an understanding of the hydrological factors, constraints and opportunities for irrigation in northern Australia: A review. CSIRO Land and Water Science Report 2008, CRC for Irrigation Futures Technical Report No. 07/07 111 pp.

[9] NLWRA (2000). Australian water resources assessment 2000. Retrieved from http://audit.ea.gov.au/anra/water/docs/national/Water_Contents.html on 12 February 2006.

[10] Petheram C., McMahon, T.A. and Peel, M.C. (2008b). Flow characteristics of rivers in northern Australia: implications for development. Submitted to Journal of Hydrology

[11] Erskine, W.E., Begg, G.W., Jolly, P., Georges, A., O’Grady, A., Eamus, D., Rea, N., Dostine. P., Townsend, S. and Padovan, A. (2003). Recommended environmental water requirements for the Daly River, Northern Territory, based on ecological, hydrological and biological principles. Supervising Scientist Report 175. (National Riverhealth Program, Environmental Flow Initiative, Technical Report 4), Supervising Scientist, Darwin NT.

[12] Paydar, Z., Cook, F.J., Xevei, E. and Bristow, K.L. (2007). Review of the current understanding of irrigation mosaics. CSIRO Land and Water Science Report No. 40/07, CRC for Irrigation Futures Technical Report No. 08/07. 38 pp.

[13] Cook, F.J., Xevi, E., Knight, J.H., Paydar, Z. and Bristow, K.L. (2008). Analysis of biophysical processes with regard to advantages and disadvantages of irrigation mosaics. CSIRO Land and Water Science Report 2008, CRC for Irrigation Futures Technical Report No. 09/07 64 pp.

[14] Camkin, J.K., Story, J. and Bristow, K.L. (2008a). An Ecologically Sustainable Development Component System to Support Irrigation Decision-Making in Northern Australia. CSIRO Land and Water Science Report No. 17/08, CRC for Irrigation Futures Technical Report No. 11/07 $19 \mathrm{pp}$.

[15] Camkin, J.K., Kellett, B.M. and Bristow, K.L. (2008b). Northern Australia Irrigation Futures: Origin, evolution and future directions for the development of a sustainability framework. CSIRO Land and Water Science Report No. 73/07, CRC for Irrigation Futures Technical Report No. 10/07 37 pp.

[16] Chesson, J., Whitworth, B., Stewart, J. and Yapp, G. (2005). Signposts for Australian Agriculture, Stage 2a: Refinement of preliminary framework 
302 Sustainable Irrigation Management, Technologies and Policies II

and industry profiles to include pathways to ESD. Final report to the National Land and Water Resources Audit, September 2005.

[17] Bammer, G. (2005). Integration and Implementation Sciences: building a new specialisation. Ecology and Society 10(2): 6. (online) URL: http://www.ecologyandsociety.org/vol10/iss2/art6/ 